\title{
Urban flood modelling in Qiqihar city based on MIKE flood
}

\author{
Jiahong Liu ${ }^{1,2}$, Zejin $\mathrm{Li}^{1}$, Weiwei Shao ${ }^{1}$, Dianyi Yan $^{3}$, and Chao Mei ${ }^{1}$ \\ ${ }^{1}$ State Key Laboratory of Simulation and Regulation of Water Cycle in River Basin, China Institute of Water \\ Resources and Hydropower Research, Beijing, 100038, China \\ ${ }^{2}$ School of Transportation and Civil Engineering and Architecture, Foshan University, \\ Guangdong, 528000, China \\ ${ }^{3}$ Yangtze River Eco-Environment Engineering Research Cente, China Three Gorges Corporation, \\ Beijing, 100038, China
}

Correspondence: Jiahong Liu (liujh@iwhr.com)

Published: 16 September 2020

\begin{abstract}
Qiqihar is a significant city on the Nen River in China, which is the main stream of the Songhua River basin. The length of the return period of Qiqihar's flood control design standard is fifty years. If a 100-year flood event happened, Qiqihar would face the risk of a burst levee. To quantitatively evaluate flood risk to the city from a burst levee or proactive flood diversion, a model for analysing flood submergence from a burst levee in the City of Qiqihar is established based on MIKE Flood. The model integrates one- and two-dimensional hydrodynamic models to implement coupled simulation. The terrain data are from city elevation data on a scale of $1: 10000$. Following local modifications made based on survey data, such as on levees, roads, and buildings, a $20 \mathrm{~m} \times 20 \mathrm{~m}$ grid of terrain data was formed as the terrain input of the model. The model simulates the water level of Nen River and the flood path, submerged time/depth/area, and duration in floodplain under three scenarios: baseline, proactive downstream flood diversion, and an upstream levee burst under a flood with a one hundredyear return period. Proactive downstream flood diversion can reduce the maximum water level by $0.068 \mathrm{~m}$ and correspondingly decrease peak flood flow by $1120 \mathrm{~m}^{3} \mathrm{~s}^{-1}$. These results provide basic information to support urban flood risk analysis and flood dispatching and management across the whole river basin.
\end{abstract}

\section{Introduction}

Flood protection levees are a vitally important hydraulic structure; if a levee bursts, it will bring immeasurable losses. The evolution of levee-bursting floods is an important factor in evaluating urban flooding risk. There are two main types of models that simulate urban flooding: static and dynamic models. Static models focus on statistical representation of simulation results while dynamic models focus on the changes that take place during the whole flooding period (Siddiqui et al., 2011). Two-dimensional hydrodynamic models are the most widely used type of model, are based on exact physical significance, and can dynamically predict and simulate the flood process (Shirvan et al., 2013). Hydrodynamic models include: the MIKE models developed by the Danish Hydraulic Institute (DHI) (Danish Hydraulic Insti- tute, 2012a, b, c, d; Wang et al., 2017), the SWMM model developed by the USA EPA (Beck, 2016), and the LISFLOOD model developed by the European Commission Joint Research Centre (Van der Knijff et al., 2010), amongst others (Teng et al., 2017). Many researchers have applied numerical simulation techniques and proposed new perspectives and concepts (Soares-Frazão et al., 2008; Chen et al., 2009). Based on two-dimensional Saint-Venant equations, different discrete methods are used to obtain different calculation stabilities, accuracies, and applications. Among them, the finite volume method has been widely used due to its conservativeness and geometric flexibility (Caleffi et al., 2003). In addition, some researchers have drawn on the methods and techniques of other academic fields, such as neural networks (Kia et al., 2012) and cellular automata (Guidolin et al., 2016). 
These methods are beneficial for decreasing calculation complexity and reducing calculation time. This paper dynamically couples the MIKE 11 HD and MIKE 21 HD models. The one- and two-dimensional models are linked through setting up a virtual river. Use of both models allows exploitation of their advantages whilst avoiding some problems - such as simulation efficiency and accuracy - that arise when the models are applied separately. Based on a 100 year return period designed flood event, the flooding process is simulated and analysed in Qiqihar City.

\section{Methodology}

The urban flood simulation system is established based on the MIKE 11 and MIKE 21 hydrodynamic (HD) models. The coupled model is called MIKE FLOOD and is used to simulate the inundation processes, duration, and inundation area within urban areas, which can provide decision support for flood management.

\subsection{MIKE 11 hydrodynamic model}

MIKE $11 \mathrm{HD}$ is mainly used for flood forecasting, dispatching measures, canal/irrigation system design, and dispatch and storm surge research. The basic aim of MIKE $11 \mathrm{HD}$ is to provide hydrological factors, such as river water level and discharge process of each river section. It is solved by onedimensional unsteady flow Saint-Venant equations based on vertical integration. Water level and discharge at each grid point are calculated alternately by the Abbott-Ionescu six points implicit scheme (Fig. 1), and the discrete equations are solved using the chasing method.

$$
\begin{aligned}
& \frac{1}{B} \frac{\partial Q}{\partial x}+\frac{\partial H}{\partial t}=q_{\mathrm{L}} \\
& \frac{\partial u}{\partial t}+\frac{\partial u}{\partial x}+g \frac{\partial H}{\partial x}+g \frac{u|u|}{C^{2} R}=0
\end{aligned}
$$

where $H$ is the water level of the channel section, $Q$ is discharge, $u$ is average velocity, $B$ is the width of the river crosssection, $q_{\mathrm{L}}$ is lateral flow, $R$ is hydraulic radius, $C$ is the Chezy coefficient, and $x$ and $t$ are position and time coordinates.

\subsection{MIKE 21 hydrodynamic model}

MIKE $21 \mathrm{HD}$ is mainly used to simulate two-dimensional free surface flow. This module can simulate changes in water level and discharge due to the impact of various forces in lakes, river mouths, and coastal areas. When the user provides terrain data, Manning coefficients, wind fields, and hydrodynamic boundary conditions, the model can simulate changes in water level and discharge in each grid. The model uses the finite difference method of alternating-difference implicit (ADI) second-term accuracy to solve the mass equation and momentum equation of dynamic flow. This model

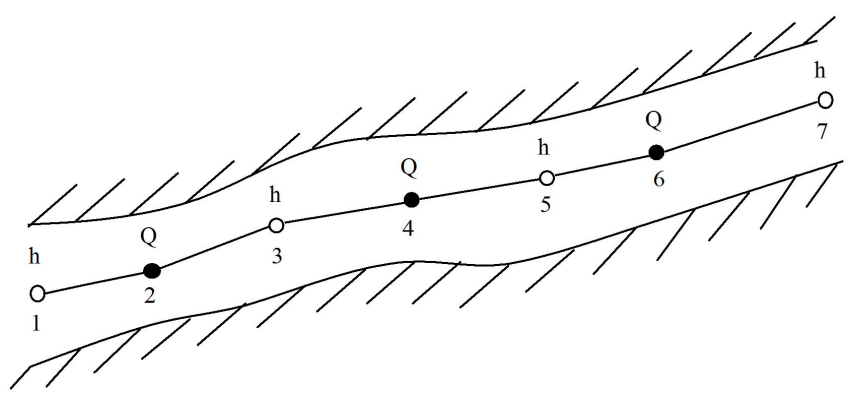

Figure 1. Water points and discharge points of the Abbott scheme.

can describe various hydraulic phenomena, such as tidal exchange, tidal flow, storm surge, whirlpools, surface undulation, dam bursts, and tsunamis. The equations take into account many factors, such as Coriolis force $(\Omega)$, wind force $(V)$, and atmospheric pressure $\left(P_{\mathrm{a}}\right)$. The variables $\zeta, d, h$, $p$, and $q$ represent water level, water depth, elevation, and discharge in the $x$ - and $y$-directions respectively.

$$
\begin{aligned}
\frac{\partial \zeta}{\partial t} & +\frac{\partial p}{\partial x}+\frac{\partial q}{\partial y}=\frac{\partial d}{\partial t} \\
\frac{\partial p}{\partial t}+ & \frac{\partial}{\partial x}\left(\frac{p^{2}}{h}\right)+\frac{\partial}{\partial y}\left(\frac{p q}{h}\right)+g h \frac{\partial \zeta}{\partial x} \\
& +\frac{g p \sqrt{p^{2}+q^{2}}}{C^{2} h^{2}}-\frac{1}{\rho_{w}}\left[\frac{\partial}{\partial x}\left(h \tau_{x x}\right)+\frac{\partial}{\partial y}\left(h \tau_{y y}\right)\right] \\
& -\Omega_{q}-f V V_{x}+\frac{h}{\rho_{x}} \frac{\partial}{\partial y}\left(p_{\mathrm{a}}\right)=0 \\
\frac{\partial q}{\partial t} & +\frac{\partial}{\partial y}\left(\frac{q^{2}}{h}\right)+\frac{\partial}{\partial x}\left(\frac{p q}{h}\right)+g h \frac{\partial \zeta}{\partial y} \\
& +\frac{g q \sqrt{p^{2}+q^{2}}}{C^{2} h^{2}}-\frac{1}{\rho_{w}}\left[\frac{\partial}{\partial y}\left(h \tau_{y y}\right)+\frac{\partial}{\partial x}\left(h \tau_{x x}\right)\right] \\
& +\Omega_{p}-f V V_{y}+\frac{h}{\rho_{x}} \frac{\partial}{\partial x y}\left(p_{\mathrm{a}}\right)=0
\end{aligned}
$$

\subsection{MIKE Flood model}

The MIKE Flood model dynamically couples the onedimensional (MIKE 11 HD) and two-dimensional (MIKE 21 HD) models. The coupled model can take advantage of the benefits of both models, and can solve problems of spatial resolution and computation that often occur when the two models are used separately. In this study, the MIKE Flood model was used to simulate the two-dimensional flood evolution path, submerged area, and duration in urban areas as well as one-dimensional river flood overtopping and levee bursts.

MIKE Flood provides two different approaches to link one-dimensional and two-dimensional models, namely standard and lateral links, which are fitted for different occasions. An important part of MIKE Flood model application is link selection and creation. 


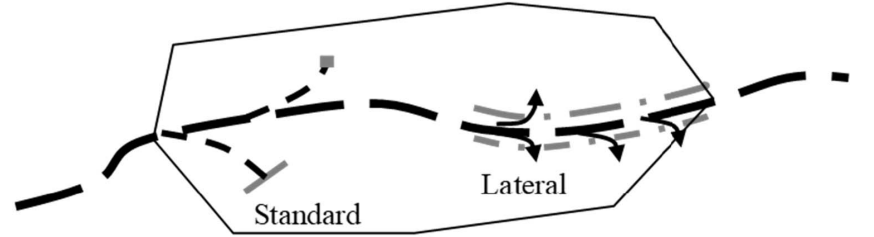

Figure 2. Standard and lateral links.

\subsubsection{Standard links}

Standard links in MIKE Flood correspond to one or more MIKE 21 grids linked to the beginning or end of MIKE 11 sections. This link can simulate submersion processes in urban inflow areas after levee bursts, by setting up a virtual river canal (Fig. 2). The section of MIKE 11 is connected to grids of MIKE 21 by Weir flow formula.

\subsubsection{Lateral links}

Lateral links are a series of grids linked with part or all of MIKE 11 side by side (Fig. 2). Flow through the lateral links is calculated using hydraulic structure formulae or water level-discharge relations. This type of link is particularly suitable for flood simulation from river to floodplain.

\section{Datasets for urban flood modelling in Qiqihar}

\subsection{Terrain data}

Basic terrain data of Qiqihar are available on a 1:10000 scale, and are supplemented with road, house, and urban residence community datasets (Fig. 3). The datasets were converted into $20 \mathrm{~m} \times 20 \mathrm{~m}$ grids using ArcGIS 9.3 software. The grid terrain data was input to the MIKE Flood model to simulate the urban submersion process in Qiqihar City.

\subsection{Manning roughness coefficient data}

Manning roughness coefficients (MRC) for urban terrain are discussed in DHI's global urban flood simulation projects in the past decades (Wang and Hartnack, 2006). Choice of different values of MRC will affect the flood peak time and to some extent the flow path within the urban area, but has little impact on the inundation area and flood depth (for a given design flood event, within the given flood duration the total breach volume could reduce as MRC increases). Roughness values are evaluated mainly on the basis of land use types. For instance, the roughness coefficient is set to 0.08 for developed areas, such as the leisure square with low buildings, gardens, and dense vegetation area; and in open space comprising grassland, sparse vegetation, streets, and pavements is set to 0.06. In similar projects in Germany, roughness coefficients in urban areas, streets, and gardens are set at 0.040 0.067 (considering the influence of pavements and vehicles parked on roads, the roughness coefficient of paths is larger); for vegetation are set at 0.05-0.2 (0.2 in dense young forest and 0.05 in open agricultural areas); and in other areas are set at $0.033-0.1$, according to landscape features. Roughness coefficients in this study are not less than 0.033 (Fig. 4).

Based on the analysis above and field investigations, the principles of determining all-terrain roughness coefficients for Qiqihar are as follows:

1. Urban roads in the simulated city are generally wider, some main roads have central reservations, and some have green verges on both sides of the road. There are generally pavements on both sides and varying amounts of vehicles on the road at any one time. Therefore, the roughness coefficient of the main roads is set at 0.06 .

2. Vegetation in parks is generally dense, so the roughness coefficient is set at 0.083 .

3. In suburbs and other open spaces, there are no buildings and land cover is mainly grass or crops, so the roughness coefficient is set at 0.06 .

4. Buildings usually interrupt water flow, which can store water inside. The roughness coefficient is set at 0.2 for buildings (houses and urban residence communities).

\subsection{Hydrological data}

Basic hydrological data were used for scenario simulation, including the once-in-a-century design flood process upstream of the Qiqihar hydrological station, the $Q-H$ curve in the downstream section (Jiangqiao hydrological station) and design flood/peak/discharge in Nen River (Fig. 5).

\section{Simulation scenarios}

There are three simulation scenarios, which are shown in Table 1 . In scenario 2 and 3, there are two burst points. The burst point of Daang embankment (Water Gate 2 in Fig. 8) is set for flood diversion, and the burst point at " $7 \mathrm{~km}$ point of west embankment" (Water Gate 1 in Fig. 8) is set for flood damage simulation. The burst point of Daang embankment is select according to the Qiqihar City Flood Prevention Scheme. Because the outside of Daang embankment is a reserved flood storage area, and the main stream of Nenjiang River turns from the southward to the westward, which is the best point for flood diversion. The burst point at " $7 \mathrm{~km}$ point of west embankment" is select by "the most unfavorable principle". In other words, if there is a collapse at this point, the city will suffer the greatest flooding. The " $7 \mathrm{~km}$ point of west embankment" is located at the upstream of Qiqihar. The flood through this point will flood over throughout the whole city, thus it is the most appropriate point by "the most unfavorable principle". 

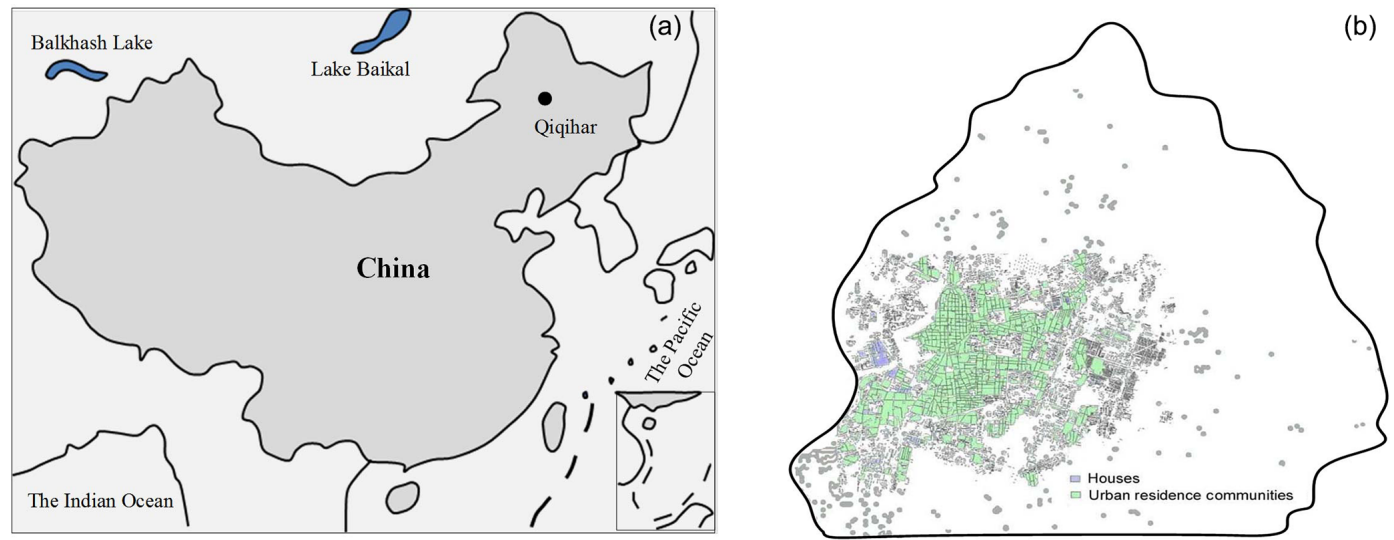

Figure 3. Location and residence data of Qiqihar (the black line around is MIKE Flood simulation grid boundary).

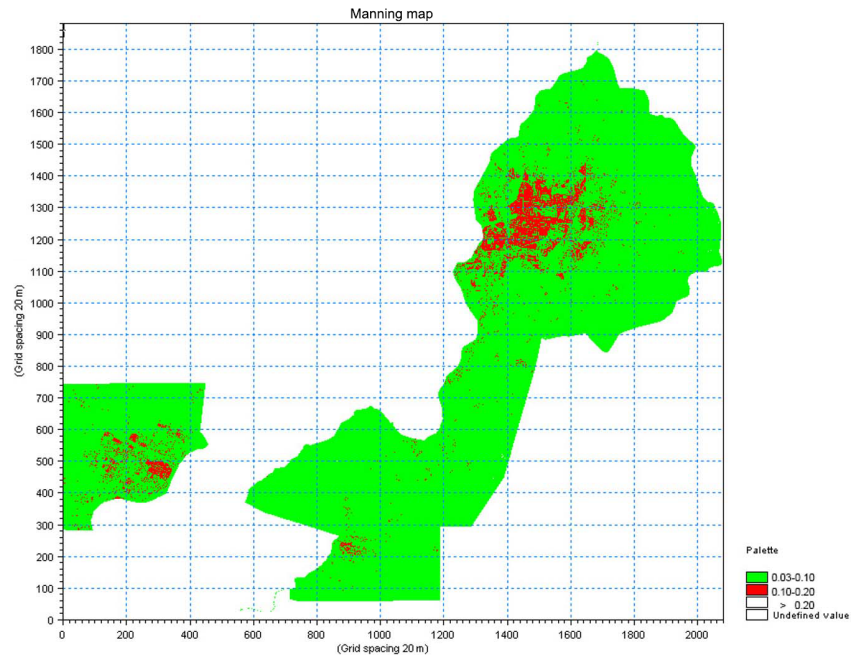

Figure 4. Distribution of Manning roughness coefficients.

\subsection{MIKE $11 \mathrm{HD}$ basic parameters}

Qiqihar City lies on the bank of the Nen River, which is upstream of Songhua River. The 1-D hydrodynamic model is established between CS31 and CS64, where the main stream of Nen River flows from 169437 to $320987 \mathrm{~m}$ (Fig. 6). The section position identification, such as 169437 and $320987 \mathrm{~m}$, is a relative distance. The start point is at the dam of Nierji reservoir, which is a large and very important reservoir in the upper reaches of the Nenjiang River.

The upstream boundary condition of the model is the discharge of a 100-year return flood that occurred in August 1998. The downstream boundary condition of the model is the $Q-H$ curve at Jiangqiao hydrological station in section CS64, which is more than $150 \mathrm{~km}$ from Qiqihar City and has little effect on the upstream water level.
Hydrograph of 100-year return period

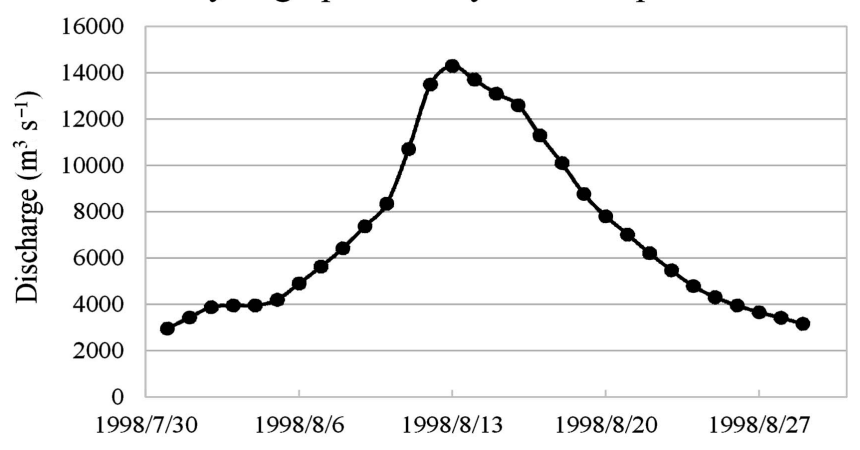

Figure 5. Design flood hydrograph of 100-year return period.

\subsection{MIKE $21 \mathrm{HD}$ basic parameters}

After considering the topography and elevation of Qiqihar City, the real land elevation is defined as $165 \mathrm{~m}$, which means regions where elevation is higher than $165 \mathrm{~m}$ are not included in the model. In order to satisfy the requirements of lateral links, the river is filled with land (because the river is calculated by a one-dimensional model and is not included in the two-dimensional simulation process).

The Nen River runs through the whole of Qiqihar City and divides the city into the main urban and Hulan Ergi regions. The model uses a $20 \mathrm{~m} \times 20 \mathrm{~m}$ grid and the total calculated areas are $2081 \times 1881 \times 400 \mathrm{~m}^{2}=1565.7 \mathrm{~km}^{2}$. The actual calculation areas cover about $430 \mathrm{~km}^{2}$, after removing the areas outside the boundary and inside the river, and urban areas that are not involved in simulation, as shown in Fig. 7. The boundary is set along the levee in the research area. The levee is surveyed and mapped by Songliao Water Conservancy Commission and provided in shape file of ArcGIS. 


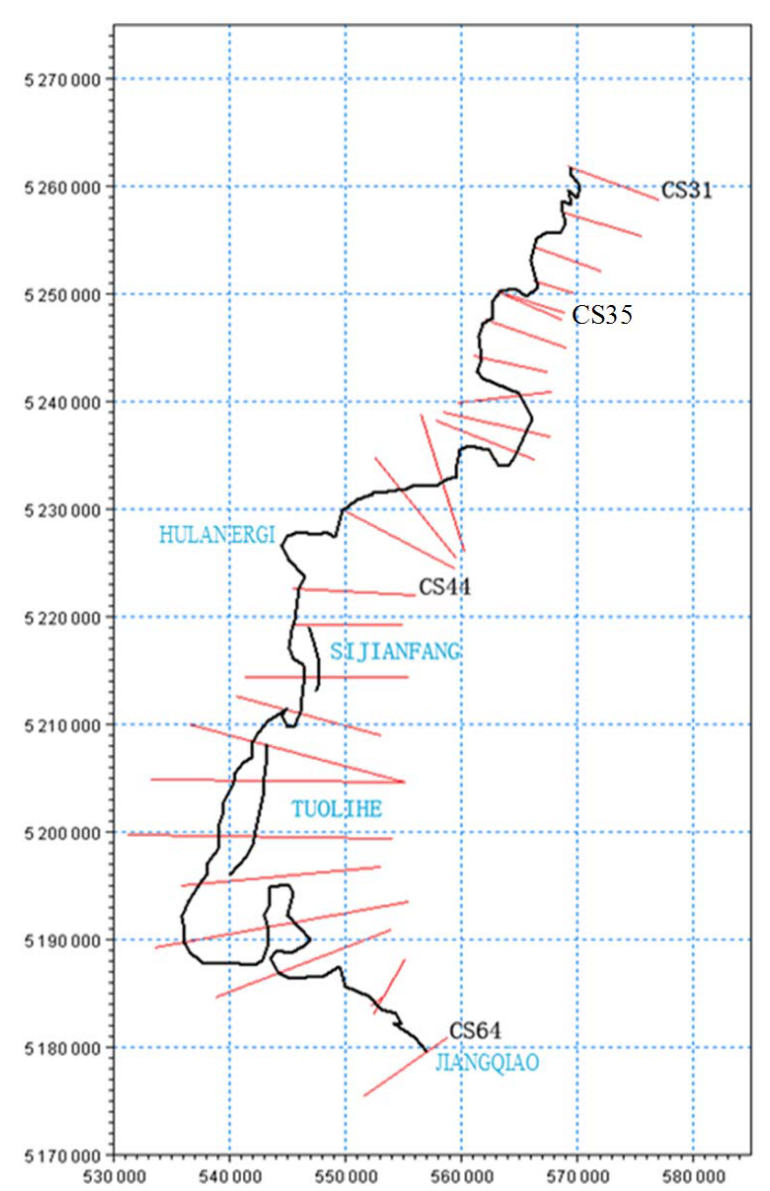

Figure 6. Main sections of one-dimensional model.

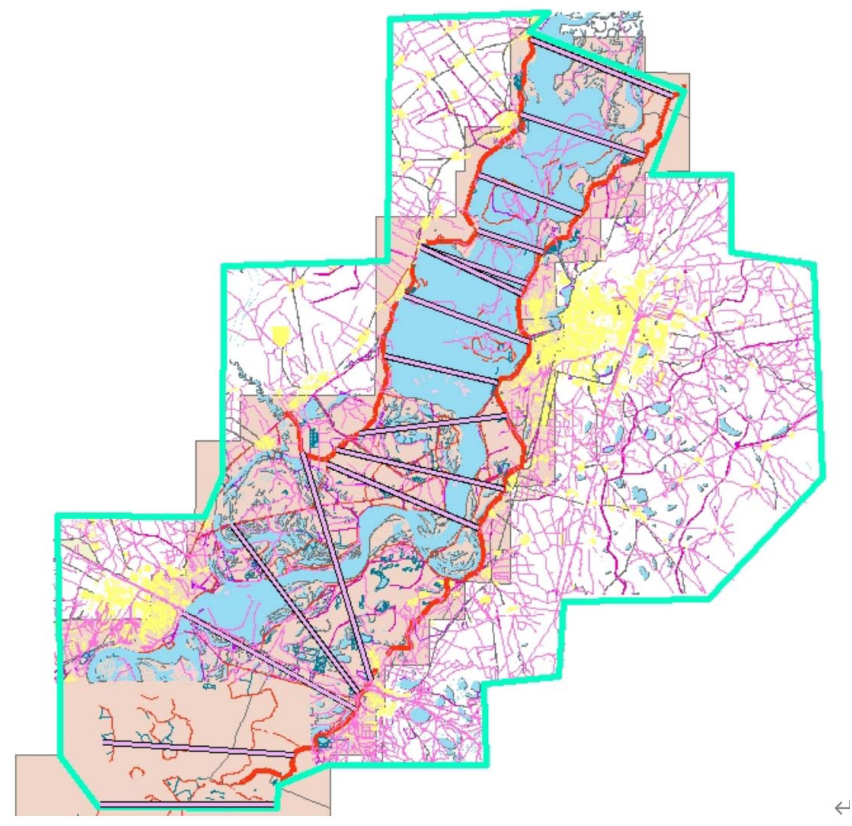

Figure 7. Simulation area of two-dimensional model in Qiqihar.

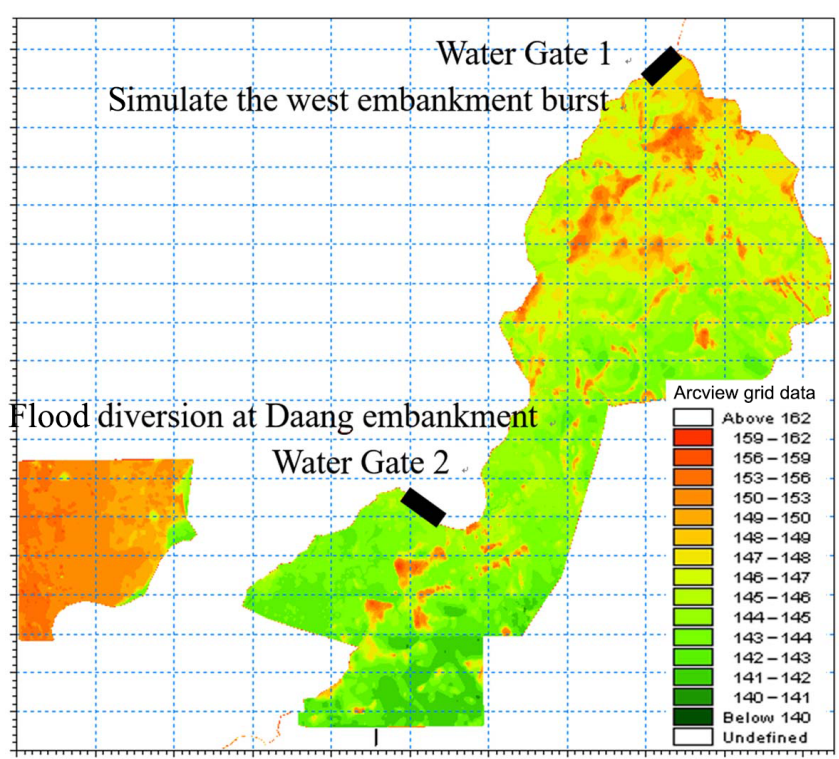

Figure 8. Simulation area of MIKE Flood and setting model links.

\subsection{MIKE Flood basic parameters}

The complete design flood process over one month is simulated, with a time step of $3 \mathrm{~s}$. In order to simulate the defence level of the Qiqihar City levee in resisting the Nen River flood and to analyse locations and times where dangerous overtopping in levees may occur, all urban levees are linked with the main stream of Nen River by lateral links.

\subsection{Levee burst simulation parameters}

The simulation of urban levee burst outfall is mainly used to analyse the urban inundation range, duration, and water depth distribution after the most dangerous levee section is broken. As there is no module in the MIKE Flood model designed especially for levee bursts, a water gate is used to simulate the burst process. When the water level in the river rises to the levee burst control threshold, the gate is opened, which corresponds to the levee having burst. The gate will not close until the flood is over. There are two water gates in this simulation, one to simulate the bursting of the west embankment in Qiqihar, and the other to simulate the flood diversion at Daang embankment (Fig. 8). MIKE 11 HD and MIKE $21 \mathrm{HD}$ are linked by adding the virtual river at the two water gates.

\section{Results}

Three scenarios were simulated (Table 1). The first is a baseline (normal) for comparison. The second simulates the flood control effect of proactive downstream flood diversion. The third simulates flooding processes when the west embankment of Qiqihar bursts. 
Table 1. Simulation scenarios for urban flooding in Qiqihar.

\begin{tabular}{llll}
\hline No. & $\begin{array}{l}\text { Flood Scheme } \\
\text { (return period) }\end{array}$ & $\begin{array}{l}\text { Flood Control } \\
\text { Measures }\end{array}$ & $\begin{array}{l}\text { Levee } \\
\text { Bursts }\end{array}$ \\
\hline 1 & 100-year & None & No \\
\hline 2 & 100-year & $\begin{array}{l}\text { Flood diversion } \\
\text { at Daang } \\
\text { embankment }\end{array}$ & No \\
\hline 3 & 100-year & None & $\begin{array}{l}\text { Bursts at 7 km } \\
\text { point of west } \\
\text { embankment }\end{array}$ \\
\hline
\end{tabular}

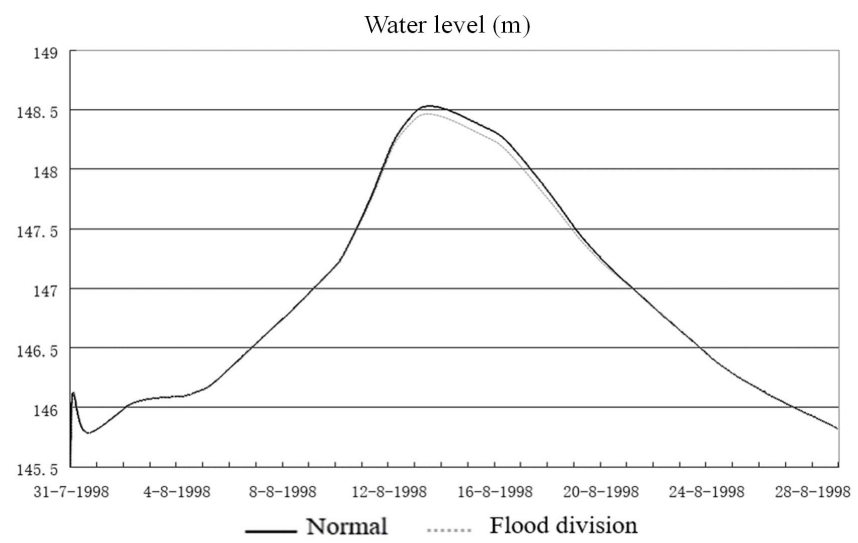

Figure 9. Water level at Qiqihar hydrological station $(P=1 \%)$.

In scenario 2, the highest water level decreases by $0.068 \mathrm{~m}$ and peak flow discharge decreases by $1120 \mathrm{~m}^{3} \mathrm{~s}^{-1}$ after flood diversion. The water level and discharge at Qiqihar hydrological station (CS35) are shown in Figs. 9 and 10. The submerged area reaches a maximum $5 \mathrm{~d}$ after implementation of flood diversion measures. The maximum submerged area is about $50 \mathrm{~km}^{2}$, and the maximum submerged depth is $3.5 \mathrm{~m}$, as shown in Fig. 11.

In scenario 3, it is assumed that the west embankment of Qiqihar bursts when the water level reaches the threshold of a 30-year return flood. The simulation results show that the discharge when the levee is broken is $328 \mathrm{~m}^{3} \mathrm{~s}^{-1}$ and the water level decreases by $0.05 \mathrm{~m}$ after the levee bursts. About $7 \mathrm{~d}$ after the burst, the submerged area reaches a maximum (nearly $100 \mathrm{~km}^{2}$ ), or about $1 / 4$ of the calculation area. The maximum depth of submersion is $3.2 \mathrm{~m}$. Figure 12 shows the submerged area and depth $7 \mathrm{~d}$ after the burst.

\section{Discussion and conclusion}

This paper has established an urban flood model based on MIKE Flood, which integrates MIKE $11 \mathrm{HD}$ and MIKE 21 HD models. MIKE Flood software is suitable for urban flood simulation, but still presents some problems, such as computational stability and the simulation of water

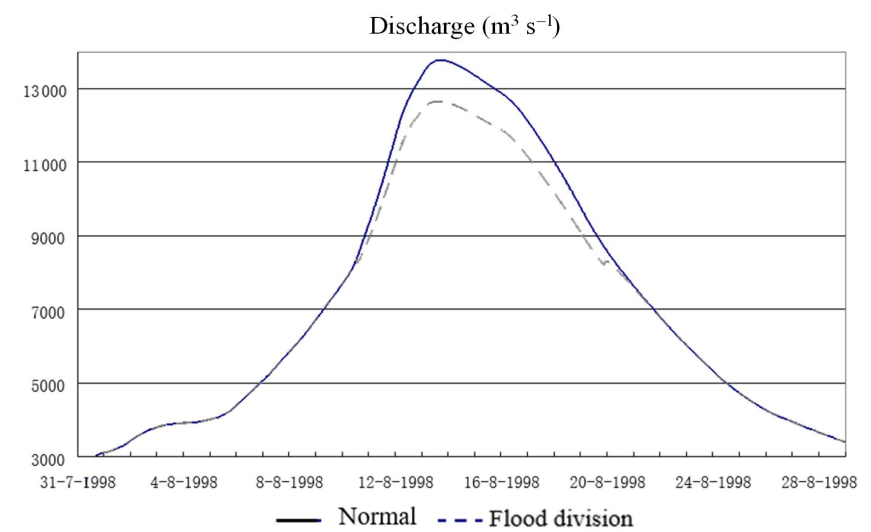

Figure 10. Discharge at Qiqihar hydrologic station $(P=1 \%)$.

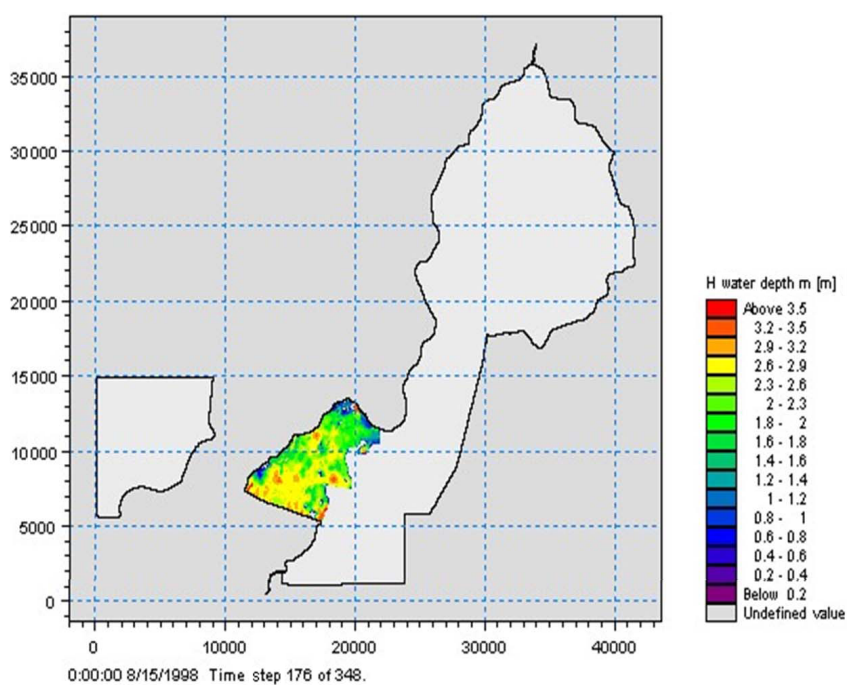

Figure 11. Submerged area in scenario 2.

inflow in buildings. Since the urban flood model simulates the process of levee bursts, flow discharge changes suddenly and rapidly and the time step must be short in order to ensure stability and accuracy of the simulation. For the twodimensional model, a time step of $3 \mathrm{~s}$ significantly decreases the calculation speed of the urban inflow process. With an increase in grid points, simulation time increases obviously. However, if the variable time step method is used, results of the two-dimensional model must be further processed following simulation.

The model simulates the flood inflow of buildings by increasing roughness in building areas, which reflects the blocking and backing effect of buildings to water. However, this method is subjective and cannot reflect actual building inflow processes. Furthermore, the roughness coefficients are sensitive to discharge and velocity calculation, which may introduce random errors.

This study has simulated three scenarios of urban flooding in Qiqihar, despite the above problems. The result is reason- 


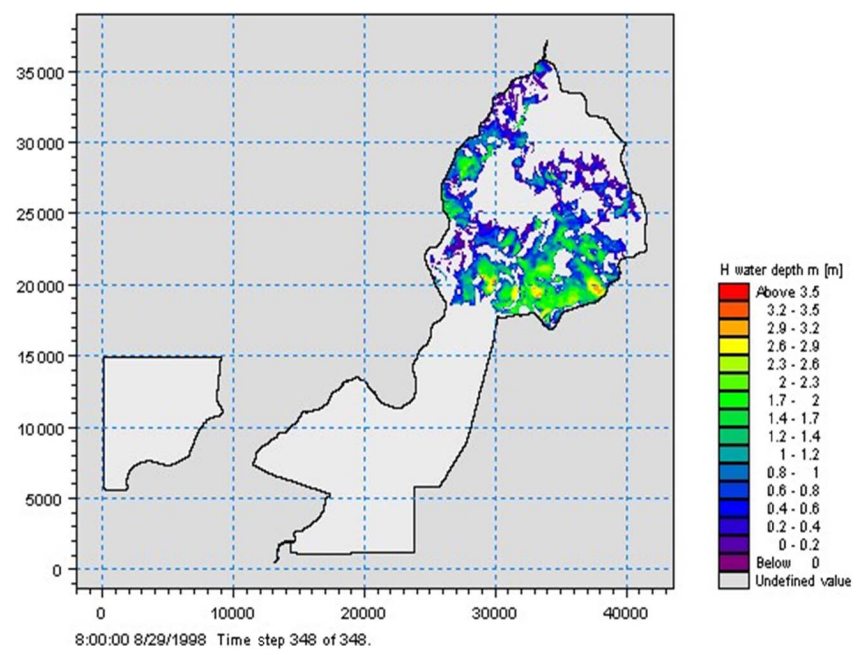

Figure 12. Submerged area in scenario 3.

able and provides key technical support for urban flood control in Qiqihar. Comparing the proactive flood diversion scenario and upstream levee burst scenario, the former has less submerged area and a better effect on flood control. In addition, the submerged areas in the former scenario are mainly in rural regions, reducing losses caused by submersion. Therefore, proactive flood diversion is an effective measure to reduce losses resulting from urban floods.

Data availability. Cross-sections geometry from Songhua River Project (2006), DEM data available on http://gdex.cr.usgs.gov/ gdex/, last access: 13 June 2018 and Digital orthophotography purchased from China Centre for Resources Satellite and Application (http://www.cresda.com/CN/, last access: 20 April 2019).

Author contributions. Methodology, JL and WS; datasets preparation, DY and CM; software and simulation, ZL and CM; writing, JL and ZL.

Competing interests. The authors declare that they have no conflict of interest.

Special issue statement. This article is part of the special issue "Hydrological processes and water security in a changing world". It is a result of the 8th Global FRIEND-Water Conference: Hydrological Processes and Water Security in a Changing World, Beijing, China, 6-9 November 2018

Acknowledgements. This study was supported by the Chinese National Natural Science Foundation (no. 51739011), the National Key Research and Development Program of China (2016YFC0401401 and 2018YFC1508203), and the Research Fund of the State Key Laboratory of Simulation and Regulation of Water Cycle in River Basin, China Institute of Water Resources and Hydropower Research (SKL2020ZY03).

Financial support. This research has been supported by the National Natural Science Foundation of China and Research Fund of the State Key Laboratory (grant nos. 51739011 and SKL2020ZY03). It is also supported by the National Key Research and Development Program of China (grant nos. 2016YFC0401401 and 2018YFC1508203)

\section{References}

Beck, J.: Comparison of three methodologies for quasi-2D river flood modeling with SWMM5, J. Water Manag. Model., C402, https://doi.org/10.14796/JWMM.C402, 2016.

Caleffi, V., Valiani, A., and Zanni, A.: Finite volume method for simulating extreme flood events in natural channels, J. Hydraul. Res., 41, 167-177, https://doi.org/10.1080/00221680309499959, 2003.

Chen, J., Hill, A. A., and Urbano, L. D.: A GIS-based model for urban flood inundation, J. Hydrol., 373, 184-192, https://doi.org/10.1016/j.jhydrol.2009.04.021, 2009.

Danish Hydraulic Institute: MIKE 11 User Manual, Danish Hydraulic Institute, Copenhagen, 2012a.

Danish Hydraulic Institute: MIKE 21 User Manual, Danish Hydraulic Institute, Copenhagen, 2012b.

Danish Hydraulic Institute: MIKE Flood User Manual, Danish Hydraulic Institute, Copenhagen, 2012c.

Danish Hydraulic Institute: MIKE Zero User Manual, Danish Hydraulic Institute, Copenhagen, 2012d.

Guidolin, M., Chen, A. S., Ghimire, B., Keedwell, E. C., Djordjević, S., and Savić, D. A.: A weighted cellular automata 2D inundation model for rapid flood analysis, Environ. Model. Softw., 84, 378394, https://doi.org/10.1016/j.envsoft.2016.07.008, 2016.

Kia, M. B., Pirasteh, S., Pradhan, B., Mahmud, A. R., and Sulaiman, W. N. A.: An artificial neural network model for flood simulation using GIS: Johor River Basin, Malaysia, Environ. Earth Sci., 67, 251-264, https://doi.org/10.1007/s12665-011-1504-z, 2012.

Shirvan, M. K. M., Alamatian, E., Bafti, F. G., and Kheradmand, Y.: Flow simulation of dam break and determining flooding zones using MIKE 21, Ecol. Environ. Conserv., 19, 679-684, 2013.

Siddiqui, Q. T. M., Hashmi, H. N., Ghumman, A. R., and Mughal, H. R.: Flood inundation modeling for a watershed in the Pothowar region of Pakistan, Arab. J. Sci. Eng., 36, 1203-1220, 2011.

Soares-Frazão, S., Lhomme, J., Guinot, V., and Zech, Y., Two-dimensional shallow-water model with porosity for urban flood modelling, J. Hydraul. Res., 46, 45-64, https://doi.org/10.1080/00221686.2008.9521842, 2008.

Teng, J., Jakeman, A. J., Vaze, J., Croke, B. F. W., Dutta, D., and Kim, S.: Flood inundation modelling: A review of methods, recent advances and uncertainty analysis, Environ. Model. Softw., 90, 201-216, https://doi.org/10.1016/j.envsoft.2017.01.006, 2017.

Van der Knijff, J. M., Younis, J., and de Roo, A. P. J.: LISFLOOD: a GIS-based distributed model for river basin scale water balance 
and flood simulation, Int. J. Geograph. Inform. Sci., 24, 189-212, https://doi.org/10.1080/13658810802549154, 2010.

Wang, F. and Hartnack, J. N.: Simulation of flood inundation in Jilin City, Songhua River Project, City, 10, 18-31, 2006.
Wang, X., Wang, W., and Huang, G.: Simulation research of urban dam break flood based on MIKE Flood model, Hydrosci. Eng., 5, 67-73, 2017 (in Chinese). 